PENGARUH PEMUNGUTAN PAJAK PERTAMBAHAN NILAI TERHADAP LAPORAN KEUANGAN Lukman Hakim, Sabil Sabil, Amin Setio Lestiningsih, Dwiyatmoko Puji Widodo IMPLEMENTASI PENGANGGARAN PARTISIPATIF DI INDONESIA Siti Meli Rahmawati, Budi Supriatono

PERKEMBANGAN SISTEM DAN TEKNIK PENGANGGARAN SEKTOR PUBLIK
BERBASIS KINERJA Chiata Oktaverina, Muhammad Fakhriansyah Kurniawan, lasha Nastitie Auliawati Rachma, Ida Farida Adi Prawira

PEMAHAMAN PELAKU BISNIS ONLINE ATAS ATURAN PERPAJAKAN: SEBUAH PRELIMINARY STUDY Agni Metta Lestari, Theresia Woro Damayanti

FAKTOR-FAKTOR YANG MEMPENGARUHI AUDIT REPORT LAG DENGAN REPUTASI KAP SEBAGAI PEMODERASI Yuliesti Rosalia, Kurnia, Lilis Ardini

STUDI KEPATUHAN WAJIB PAJAK ORANG PRIBADI WIRAUSAHAWAN DI KABUPATEN KULON PROGO Arinda Listya Palupi, Amir Hidayatulloh

FAKTOR-FAKTOR YANG MEMPENGARUHI EFEKTIVITAS FUNGSI INTERNAL PADA PEMERINTAH DAERAH X Faiz Zamzami, Rumiyati Rumiyati, Rudi Prasetya Timur

MANFAAT INFORMASI LAPORAN KEUANGAN BERBASIS AKRUAL DALAM PENGAMBILAN KEPUTUSAN Dedi Sutrisna Syah Putra, Sri Mulyani

PENGARUH RISIKO KEUANGAN DAN NILAI PERUSAHAAN TERHADAP PERATAAN
LABA

Tevi Leviany, Wiwin Sukiati, Melinda Syahkurah 


\title{
JURNAL SIKAP (Sistem Informasi, Keuangan, Auditing Dan Perpajakan)
}

\section{Editorial Board}

\section{Chief Editor}

Sukadwilinda, Universitas Sangga Buana, Indonesia

\section{Managing Editor}

Erik Nugraha, Universitas Sangga Buana, Indonesia

\section{Editorial Board}

Bambang Susanto, Universitas Sangga Buana, Indonesia Yana Setiawan, Universitas Pendidikan Indonesia, Indonesia

Yuli Nawangsasi, Universitas Sangga Buana, Indonesia

Surya Ansori, Universitas Sangga Buana, Indonesia

Audita Setiawan, Universitas Sangga Buana, Indonesia

\section{Editorial Review Board}

Prof. Dr. Sukrisno Agoes., MM., Ak., CA., CPA, Universitas Tarumanagara, Indonesia

Dr. Tettet Fitrijanti., SE., M.Si., Ak., CA, Universitas Padjadjaran, Indonesia

Dr. Budi S Purnomo., SE., MM., M.Si, Universitas Pendidikan Indonesia, Indonesia

\section{Proofreading}

Reza Saeful Rachman, Universitas Sangga Buana, Indonesia

\author{
Web \& Layout Editors
}

Intan Mustikasari, Universitas Sangga Buana, Indonesia

\section{Kebijakan Editorial}

Jurnal SIKAP (Sistem Informasi, Keuangan, Auditing dan Perpajakan) merupakan jurnal yang dikelola dan diterbitkan oleh Program Studi Akuntansi Fakultas Ekonomi Universitas Sangga Buana YPKP yang memuat hasil penelitian dan pemikiran para cendikiawan dalam bidang Ilmu Akuntansi baik para akademisi maupun praktisi. Jurnal SIKAP (Sistem Informasi, Keuangan, Auditing dan Perpajakan) terbit secara berkala dua kali dalam setahun yaitu pada bulan Oktober dan April.

Published by:

Program Studi Akuntansi

Fakultas Ekonomi

Universitas Sangga Buana YPKP

Jln. PHH. Mustofa Nomor 68 Kota Bandung, Jawa Barat, Indonesia - 40124

p-ISSN: 2541-1691, e-ISSN: 2599-1876

http://jurnal.usbypkp.ac.id/index.php/sikap/ 


\section{DAFTAR ISI}

PENGARUH PEMUNGUTAN PAJAK PERTAMBAHAN NILAI TERHADAP LAPORAN

KEUANGAN

Lukman Hakim, Sabil Sabil, Amin Setio Lestiningsih, Dwiyatmoko Puji Widodo

IMPLEMENTASI PENGANGGARAN PARTISIPATIF DI INDONESIA

$12-20$

Siti Meli Rahmawati, Budi Supriatono

PERKEMBANGAN SISTEM DAN TEKNIK PENGANGGARAN SEKTOR PUBLIK BERBASIS

KINERJA

Chiata Oktaverina, Muhammad Fakhriansyah Kurniawan, Iasha Nastitie Aulliawati Rachma, Ida

Farida Adi Prawira

PEMAHAMAN PELAKU BISNIS ONLINE ATAS ATURAN PERPAJAKAN: SEBUAH

$29-43$

PRELIMINARY STUDY

Agni Metta Lestari, Theresia Woro Damayanti

FAKTOR-FAKTOR YANG MEMPENGARUHI AUDIT REPORT LAG DENGAN REPUTASI KAP SEBAGAI PEMODERASI

Yuliesti Rosallia, Kurnia, Lillis Ardini

STUDI KEPATUHAN WAJIB PAJAK ORANG PRIBADI WIRAUSAHAWAN DI KABUPATEN

KULON PROGO

Arinda Listya Pallupi, Amir Hidayatulloh

FAKTOR-FAKTOR YANG MEMPENGARUHI EFEKTIVITAS FUNGSI INTERNAL PADA

66-79 PEMERINTAH DAERAH X

Faiz Zamzami, Rumiyati Rumiyati, Rudi Prasetya Timur

MANFAAT INFORMASI LAPORAN KEUANGAN BERBASIS AKRUAL DALAM

$80-94$

PENGAMBILAN KEPUTUSAN

Dedi Sutrisna Syah Putra, Sri Mulyani

PENGARUH RISIKO KEUANGAN DAN NILAI PERUSAHAAN TERHADAP PERATAAN LABA

95-101

Tevi Leviany, Wiwin Sukiati, Melinda Syahkurah 